\title{
The Impact of Feeder Type on the Honeybee Colonies (Apis mellifera L.) and Hive Operation During Colony Feeding
}

\author{
Zewdu Ararso Hora*, Taye Negera, Kibebew Wakjira \\ Oromia Agricultural Research Institute, Holeta Bee Research Center, Holeta, Ethiopia \\ Email address: \\ zewdu402@yahoo.com (Z.A. Hora) \\ ${ }^{*}$ Corresponding author

\section{To cite this article:} \\ Zewdu Ararso Hora, Taye Negera, Kibebew Wakjira. The Impact of Feeder Type on the Honeybee Colonies (Apis mellifera L.) and Hive \\ Operation During Colony Feeding. American Journal of Bioscience and Bioengineering. Vol. 9, No. 3, 2021, pp. 88-92. \\ doi: $10.11648 /$ j.bio.20210903.15
}

Received: April 6, 2021; Accepted: May 29, 2021; Published: June 22, 2021

\begin{abstract}
Several types of feeder have been used by beekeepers for feeding their colonies with sugar syrup during dearth periods. However, each feeder type has its benefits and drawbacks both for the bees and beekeepers. The effects of different feeder types on honeybee colonies well-being and their conveniences for feeding by the beekeepers were investigated. Time required to feed a colony, amount of feed consumed, number of dead bees during feeding, number of dead bees in/on the feeder when removed, disturbance and convenience based on technicians' opinion were compared. Accordingly, significantly $(p<0.000)$ shortest time $(40.45 \mathrm{sec})$ was obtained for top feeder than bucket $(71.25 \mathrm{sec})$ and frame $(137.80 \mathrm{sec})$ feeders. Likewise, significantly $(p<0.001)$ less number of dead bees $(2.50)$ were observed while feeding a colony using top feeder as compared to bucket and frame feeders in which 5.45 and 11.00 dead bees were recorded under hive stand, respectively. Moreover, no dead bee was recorded on the top surface of top feeder compared to frame feeder in which 1.60 dead bees were counted. However, feeder type did not affect the amount of sugar syrup consumed and colony survival during the experiment. Regarding bee technicians' opinion, top feeder is highly convenient to feed colonies with a minimum colony disturbance and reaction. Thus, the current results indicate that feeding colonies using top feeder is less time consuming, inflicts less damage to the bees, and more convenient feeding method for the beekeeper.
\end{abstract}

Keywords: Bucket Feeder, Colony Feeding, Frame Feeder, Sugar Syrup, Top Feeder

\section{Introduction}

Beekeeping in Ethiopia traditionally has been practiced following the flowering events which provide sufficient quantities of nectar and pollen to stimulate colonies build up and maintain optimum colony populations. However, nowadays, maintaining optimum colony population during dearth period with limited floral resources is becoming a major problem for the beekeepers. Shortage of floral resource availability leads to declining of colony's population eventually resulting in weaker colonies. Such colonies are also vulnerable to absconding, natural pests and predators of honeybees [1], as nutritional stress known to act synergistically with other environmental stressors [2]. The first option to minimize dearth period colony starvation is providing supplementary feeds [3]. Providing sugar syrup as supplementary feeding to honeybee colonies can be one of the management option during dearth period [4]. Sugar syrup feeding is popular and the most effective during dearth periods to maintain optimum colony population [4] that ensures early colony build up to produce surplus honey during honey flow season $[5,6]$. To this end, different types of feeders and feeding methods have been invented, tested and used for feeding honeybee colonies of different races with varying behaviors. However, the types of feeder used depend on materials available at the beekeepers' level and possibly on the types of commercial feeders on the local markets. Thus, the primary choice of feeder type is the primary management decision to be made by the majority of beekeepers.

In Ethiopia, several types of feeder have been used to feed honeybee colonies, during dearth periods. However, the effects of the feeders on the well-being of honeybee colonies, time consumption during feeding and convenience 
in terms of hive operation work and reaction of bees have not been evaluated under local honeybee colonies. Therefore, the aim of this study is to evaluate whether feeder types (top feeder, bucket feeder and frame feeder) affect time required to feed a colony, amount of feed consumed, number of dead bees during hive operation for feeding, number of dead bees in/on the feeder when removed, colony disturbance and absconding rate in relation to our local honeybee behavior. In addition to these, we also included bee technicians' opinion (preference) on the convenience of each feeding mode for honeybee colony feeding.

\section{Materials and Methods}

\subsection{Description of the Study Area}

The study was conducted at two experimental apiaries (Holeta: $9^{0} 30^{\prime} \mathrm{N}$ and $38^{\circ} 30^{\prime} \mathrm{E}$, Elevation $2450 \mathrm{~m}$ and 30 kilometers west of Addis Ababa; Bako: $9^{0} 6^{\prime} \mathrm{N}$ and $37^{\circ} 9^{\prime} \mathrm{E}$, Elevation $1650 \mathrm{~m}$ and 258 kilometers west of Addis Ababa) of Holeta Bee Research Center in Oromia Regional State of Ethiopia.

\subsection{Preparation of the Feeders}

A total of 10 bucket feeders, 10 plastic frame feeders and 10 top feeders were obtained for the experiment. Bucket feeders with volume of $2 \mathrm{~L}$ were purchased from local market. Plastic frame feeders that fit with the dimensions of the hives were obtained from bee equipment importer. Top feeder, an inner cover made up of plywood with the dimensions to perfectly fit with wooden rims dimensions, similar to the outer hive chambers were constructed at Holeta Bee Research Center's workshop (Figure 1). The $2.5 \mathrm{~cm}$ high wooden rims (edges) on the outside provide sufficient room for supplementary feeding (pollen or sugar syrup) to bees on the top surface. The inner cover has a rectangular open space of about $5 \mathrm{~cm} \times 8 \mathrm{~cm}$ at its center with a tight ledge of $1.5 \mathrm{~cm}$ high and $3 \mathrm{~cm}$ wide erected to facilitate provision of supplementary feeds. The open space allows bees' access to the space between the inner cover and the hive lid during feeding.

\subsection{Establishing Experimental Colonies}

For this study, well-established local honeybee (Apis mellifera) colonies were used at two experimental Apiaries of Holeta Bee Research Center (Holeta and Bako). The colonies were kept in standard Zander hives with one additional box (super) and each box containing 10 frames. During flowering season, in last week of October 2018, colonies were subjectively estimated for their strength based on number of frames covered by adult bees, brood, nectar and honey, and pollen, as described elsewhere [7]. Then, 15 honeybee colonies with approximately uniform strength were selected and randomly assigned to the three treatment groups (bucket feeder, frame feeder and top feeder) with five replications at each apiary.

\subsection{Evaluation of Feeder Types}

The feeding experiment was started in January 2019 and conducted during identified dearth periods using an objective mode which uses empirical measures. A subjective mode that relies on visual estimates by one or more observers was also employed to evaluate parameters like disturbance and convenience to a beekeeper based on the observers' opinion.

Bucket feeder: Sugar syrup was prepared in 1:1 (sugar to water) ratio. One and half liter of the syrup was poured into each bucket feeder and some grass was placed on the top of the syrup to protect bees from drowning down while taking up the feed. A $1 \mathrm{~m} \times 1 \mathrm{~m}$ plastic sheet was placed under each hive stand to collect data on the number of dead bees on the next morning after feeding. The hives were opened and at least four existing frames with empty combs were removed and bucket feeder with $1.5 \mathrm{~L}$ of sugar syrup was placed into the hive and the hive was closed. After three days, the colonies were checked for the dead bees and the feeders were removed. Time taken to pour the syrup, open the hive, remove the frames, close the hive and transport the frames taken away from the hives and remove the feeder was recorded at each step. The time recorded for hive opening and frame removal did not include in the preparation, transportation and addition of supers (additional boxes) when needed. Similarly, feeder removal did not include removal of the supers (additional boxes) and their transportation, which required one additional working day. Moreover, number of dead bees under each hive stand, amount of feed over left, number of colony absconded (if any), number of dead bees in/on the feeder at a time of feeder removal, observations on level of disturbance and bee technicians' opinion while feeding and feeder removal were recorded.

Frame feeder: Plastic frame feeder with the capacity of $2 \mathrm{~L}$ was used. Like in bucket feeder, sugar syrup was prepared in 1:1 (sugar to water) ratio. Unlike in bucket feeder, the hive was opened and one existing frames with empty comb was removed to place the frame feeder into one side of the hive and $1.5 \mathrm{~L}$ sugar syrup was poured into the frame feeder after placing the feeder in the hive. All other procedures, data recordings and observations were made as described for bucket feeder.

Top feeder: Here, an inner cover made up of plywood with wooden rims that serves both as inner cover and top feeder was used. Sugar syrup was prepared as describe under bucket feeder. The prepared syrup was taken closer to the hive. The lid of the hive was opened and 1.5 L sugar syrup was poured on the top surface of the inner cover/top feeder (Figure 2). The hive was finally closed with the outer lid. Unlike the two feeders, there is no need to remove frames or add extra hive body (super) for the feeder and also no need of feeder removing at all. Otherwise, all other procedures, data recordings and observations were made as for bucket feeder described above. The conveniences of the feeder types for the beekeeper in relation to bees' reaction were observed. For this purpose, five experienced bee technicians were allowed to run the feeding experiment every time and a technician 
given a chance to feed one colony from each treatment (feeder type) during every feeding. Their response on the convenience of each feeder type was recorded as less convenient, medium and highly convenient.
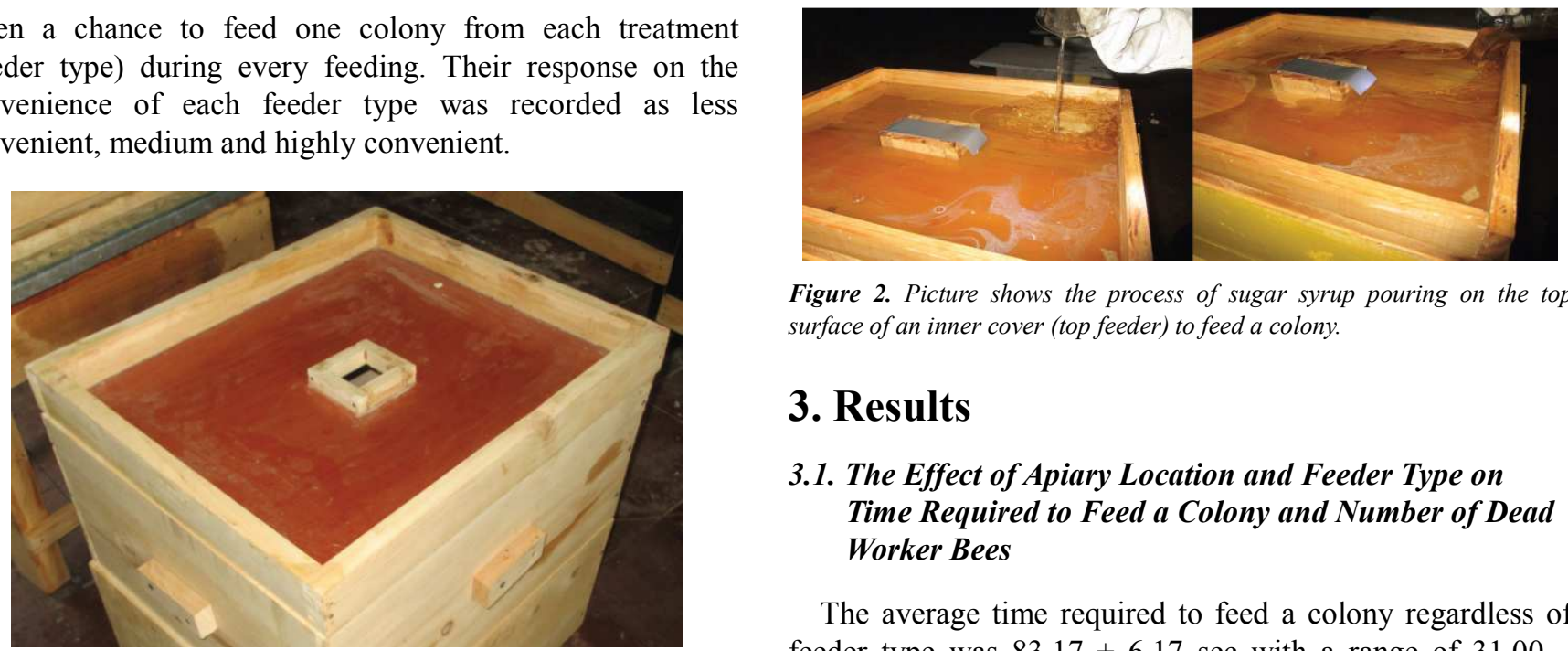

Figure 2. Picture shows the process of sugar syrup pouring on the top surface of an inner cover (top feeder) to feed a colony.

\section{Results}

\subsection{The Effect of Apiary Location and Feeder Type on Time Required to Feed a Colony and Number of Dead Worker Bees}

The average time required to feed a colony regardless of feeder type was $83.17 \pm 6.17 \mathrm{sec}$ with a range of $31.00-$ $180.00 \mathrm{sec}(\mathrm{n}=60)$. The average time required to feed a colony was not significantly varied between apiaries $(p>0.65)$ (Table 1). Similar results were obtained when comparing number of dead bees under the hive stand a day after feeding and at a time of feeder removal $(p>0.12$ and $p>1$, respectively). However, the results were significantly varied within each individual apiary. At Holeta, comparison among feeder types (time for placing the feed and removing the feeder in each colony) confirmed that significantly longest time was recorded for frame feeder, followed by bucket feeder, and the shortest time was for the top feeder $(F=$ 19.62, $d f=(2,27), p<0.000)$. At Bako sub-site, similar trend of significant decrease in time of hive operation to feed a colony was observed from using frame feeder to top feeder $(F=185.38, d f=(2,27), p<0.000)$ (Table 2). As for the duration of hive operation, the number of dead worker bees was significantly higher when using frame feeder as compared with using top feeder and bucket feeder at both locations (Table 2). Pearson's chi-square was used to test the relationship between the convenience to feed and feeder types.

Table 1. Mean \pm standard error of time required to feed a colony (sec), and number of dead bees under hive stand and in/on a feeder a day after feeding bees and at a time of feeder removal, respectively, across apiary sites. Within a row, similar superscript upper case letter shows non-significant difference between location means at $p<0.05$.

\begin{tabular}{|c|c|c|}
\hline \multirow{2}{*}{ Variables } & \multicolumn{2}{|l|}{ Locations } \\
\hline & Holeta & Bako \\
\hline Time require to feed a colony & $80.33 \pm 7.30^{\mathrm{A}}$ & $86.00 \pm 10.04^{\mathrm{A}}$ \\
\hline Number of dead bees under hive stand & $4.77 \pm 0.98^{\mathrm{A}}$ & $7.87 \pm 1.69^{\mathrm{A}}$ \\
\hline Number of dead bees in/on a feeder at a time of feeder removing & $0.60 \pm 0.16^{\mathrm{A}}$ & $0.60 \pm 0.16^{\mathrm{A}}$ \\
\hline
\end{tabular}

Table 2. Effects of different feeder types on time required to feed a colony (sec), and number of dead bees under hive stand and in/on a feeder a day after feeding bees and at a time of feeder removal, respectively when each apiary is analyzed separately. Values are mean \pm standard error of treatments. Within a column, means followed by different upper case superscript letters indicate significant differences among treatments.

\begin{tabular}{|c|c|c|c|c|c|c|}
\hline \multirow{2}{*}{ Feeder type } & \multicolumn{2}{|l|}{ TRF } & \multicolumn{2}{|l|}{ NDBUH } & \multicolumn{2}{|l|}{ NDBIOF } \\
\hline & Holeta & Bako & Holeta & Bako & Holeta & Bako \\
\hline Top feeder & $42.90 \pm 1.86^{\mathrm{C}}$ & $38.00 \pm 1.84^{\mathrm{C}}$ & $1.60 \pm 0.58^{\mathrm{B}}$ & $3.40 \pm 0.78^{\mathrm{B}}$ & $0.00 \pm 0.00^{\mathrm{B}}$ & $0.00 \pm 0.00^{\mathrm{B}}$ \\
\hline Bucket feeder & $81.10 \pm 2.46^{\mathrm{B}}$ & $61.40 \pm 4.32^{\mathrm{B}}$ & $4.90 \pm 0.89^{\mathrm{B}}$ & $6.00 \pm 1.50^{\mathrm{B}}$ & $0.20 \pm 0.13^{\mathrm{B}}$ & $0.20 \pm 0.13^{\mathrm{B}}$ \\
\hline Frame feeder & $117.00 \pm 14.16^{\mathrm{A}}$ & $158.60 \pm 6.64^{\mathrm{A}}$ & $7.80 \pm 2.43^{\mathrm{A}}$ & $14.20 \pm 4.22^{\mathrm{A}}$ & $1.60 \pm 0.27^{\mathrm{A}}$ & $1.60 \pm 0.27^{\mathrm{A}}$ \\
\hline$p$ value & 0.000 & 0.000 & 0.028 & 0.019 & 0.000 & 0.000 \\
\hline
\end{tabular}

$\mathrm{TRF}=$ Time required to feed a colony, NDBUH $=$ Number of dead bees under hive stand, NDBIOF $=$ Number of dead bees in/on a feeder at a time of feeder removal 
Analyzes of time required to feed a honeybee colony, and number of dead bees under hive stand and in/on a feeder a day after feeding bees and at a time of feeder removal, respectively were performed based on feeder types pooling the data from both apiaries. The time elapsed to feed a colony using different feeders was significantly different among feeder types $(p<0.000)$. The longest duration was recorded for frame feeder $(137.80 \pm 8.98 \mathrm{sec})$, while the shortest was for top feeder $(40.45 \pm 1.39 \mathrm{sec})$. Again, the biggest number of dead worker bees was counted when feeding colonies using frame feeder compared to top feeder and bucket feeder (Table 3).

Table 3. Effects of three feeder types on time required to feed a colony (sec), and number of dead bees under hive stand and in/on a feeder a day after feeding bees and at a time of feeder removal, respectively, for the pooled data from both locations. Values are mean \pm standard error of feeder types. Within a column, means followed by different upper case superscript letters indicate significant differences among feeder types.

\begin{tabular}{llll}
\hline Feeder type & TRF & NDBUH & NDBIOF \\
\hline Top feeder & $40.45 \pm 1.39^{\mathrm{C}}$ & $2.50 \pm 0.52^{\mathrm{B}}$ & $0.00 \pm 0.00^{\mathrm{B}}$ \\
Bucket feeder & $71.25 \pm 3.31^{\mathrm{B}}$ & $5.45 \pm 0.85^{\mathrm{B}}$ & $0.20 \pm 0.92^{\mathrm{B}}$ \\
Frame feeder & $137.80 \pm 8.98^{\mathrm{A}}$ & $11.00 \pm 2.48^{\mathrm{A}}$ & $1.60 \pm 0.18^{\mathrm{A}}$ \\
$p$ value & 0.000 & 0.001 & 0.000 \\
\hline
\end{tabular}

$\mathrm{TRF}=$ Time required to feed a colony, NDBUH $=$ Number of dead bees under hive stand, NDBIOF $=$ Number of dead bees in/on a feeder at a time of feeder removal

\subsection{The Effects of Feeder Type on Amount of Feed Consumed, Colony Absconding, Disturbance and Convenience}

To compare the effects of feeder types on the colonies feed consumption, an observation was made on the third day for the feed over left. Accordingly, there was no sugar syrup left in any of the feeder. Moreover, there was no absconding event occurred during the experiment. However, using top feeder allowed sugar syrup feeding with minimal disturbance to the colony when visually observed from observations made during the feeding processes (Figure 3). Furthermore, the top feeder was also found highly convenient $\left(\chi^{2}=81.60, d f=4, p<0.000\right)$ compared to bucket and frame feeders when subjectively evaluated by bee technicians involved during the feeding operation.

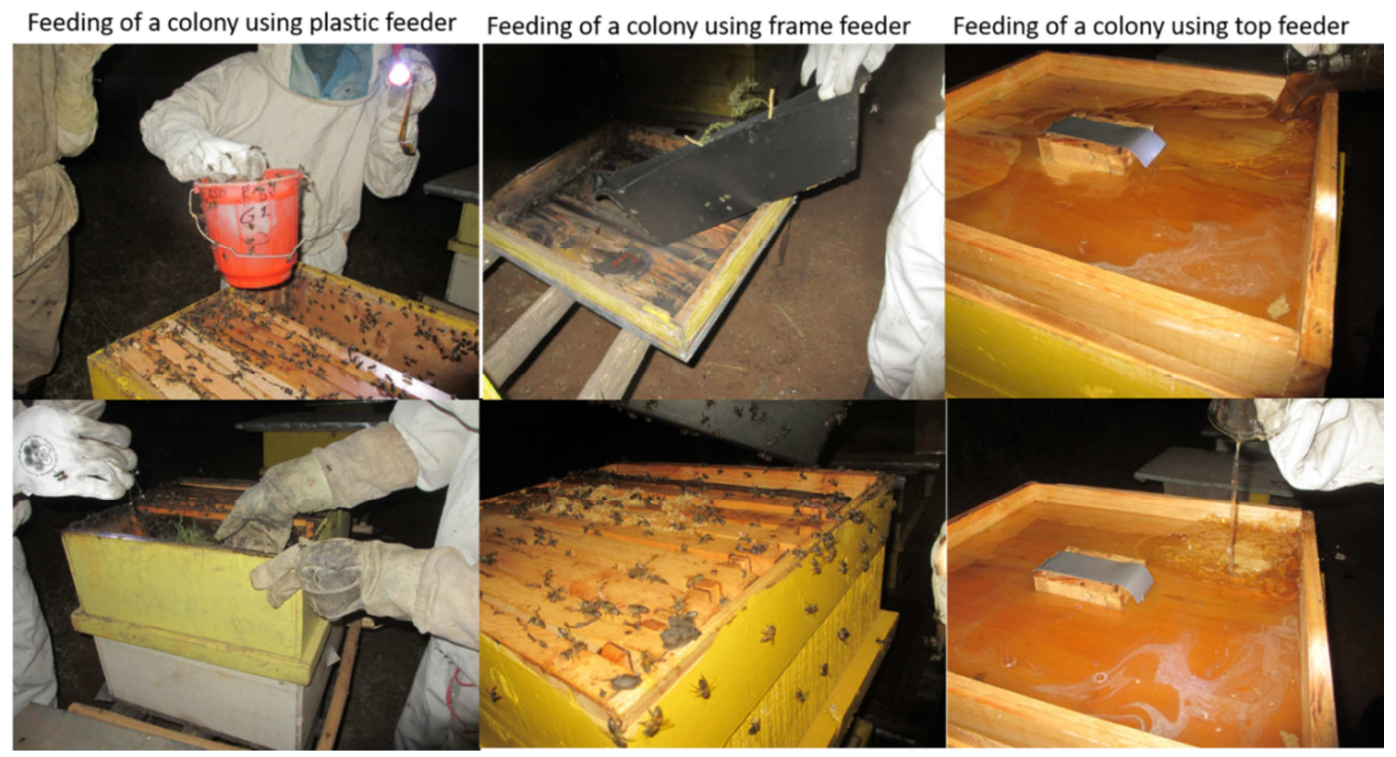

Figure 3. Pictures show feeding of honeybee colonies using different types of feeder and the extent of colony disturbances.

\section{Discussion}

In different parts of the world many different methods and types of feeder have been used by beekeepers for feeding sugar syrup to honeybee colonies. Using each feeder type has its advantages and disadvantages [9]. The problem of the beekeeper having to open and operate each hive while feeding colonies internally, which is a time consuming and an extra work if there are many colonies [10]. In this result, this is reflected by varying time of hive operation using three different feeder types. Colony feeding using top feeder relatively consumed less time as compared to using the bucket and frame feeders, which is consistent with the previously reported time used to feed one hive [11]. The shortest time to feed a colony may associate with using inner cover as top feeder, which did not require the removal of the existing frame or addition of extra super for a feeder as for frame and bucket feeders, respectively. In addition, when inner cover is used as a feeder, it makes opening of outer cover (hive lid) much easier than removing a propolized hive lid used without inner cover. Even removing a propolized inner cover is much easier because a hive tool can get easily 
in between the cover and the hive body than trying to open a propolized hive lid. As the feeder (inner cover) size is just right to fit to the hive body leaving no gap for bees and the time used to open the hive is so short, no bees would come out to sting and also bees could not fly out (see Figure 3). Moreover, once top feeder is installed in position, it is easy to refill the syrup at any time, Thus, top feeder allows colony feeding with a minimum disturbance to the colony. Finally, such conditions give a chance for the beekeepers to feed their bees even without wearing beekeeping closing [10].

In general, Ethiopian honeybees are defensive, and defending the honeybee colony and its resources is crucial for maintaining the colony integrity $[12,13]$. The defensive behavior makes colony management difficult [13], as hive operation can create provocative situation to the colony $[13,14]$. To this end, taking out a frame from a hive and inserting a plastic frame feeder and a bucket in the place is thought to provoked the bees to defend in mass [15], which might be resulted in significantly higher number of dead bees. This together with its demanding of long time hive operation, suggests that using frame and bucket feeders to feed defensive local honeybee colonies is less useful. Although a compressive comparison of the cost and benefits over several years of use by a diversity of beekeepers (with varying levels of experience) to fully access the longevity of the equipment and productivity under beekeepers' condition is required for the future, top feeder is the best type from its ease of colony management point of view.

\section{Conclusion}

This study takes the first steps in evaluating the effects of feeder type on local honeybee behavior and convenience of the feeders to the beekeeper, and our results suggest that top feeder likely have more place for Ethiopian beekeepers for its less time consuming, inflicts less damage to the bees, and more convenient feeding method. Based on this finding, top feeder is recommended as suitable feeder for local honeybees and beekeepers which reduces feeding time, as well as days required to feed a given number of honeybee colonies.

\section{Conflicts of Interest}

The authors of this paper do hereby disclose that there are no conflicts of interest whatsoever in relation to this article.

\section{Acknowledgements}

The authors acknowledge the Oromia Agricultural Research Institute through the Holeta Bee Research Center for funding this research.

\section{References}

[1] Wakjira, K., Kumsa, T., Negera, T., and Debela, S. Investigating fundamental causes of Ethiopian honeybee (Apis mellifera L.) colony absconding: ranked beekeeping constraints of the country, unpublished data.
[2] Tosi, S., Nieh, J. C., Sgolastra, F., Cabbri, R., \& Medrzycki, P (2017). Neonicotinoid pesticides and nutritional stress synergistically reduce survival in honey bees. Proceedings of the Royal Society B: Biological Sciences 284: 20171711.

[3] Neupane, K., Thapa, R. (2005) Alternative to Off-season Sugar Supplement Feeding of Honeybees. Journal of Institute of Agriculture and Animal Sciences 26: 77-81. doi: 10.3126/jiaas.v26i0.615.

[4] Somerville, D. (2014) Feeding sugar to honey bees. Primefact 1343, New South Wale Government, Department of Primary Industry. Available at: https://www.dpi.nsw.gov.au/_data/assets/pdf_file/0018/5322 60/Feeding-sugar-to-honey-bees.pdf.

[5] Sihag, R. C., Gupta, M. (2013) Testing the effects of some pollen substitute diets on colony build up and economics of beekeeping with Apis mellifera L. Journal of Entomology 10: 120-135. doi: 10.3923/je.2013.120.135.

[6] Standifer, L. N., Moeller, F. E., Kauffeld, N. M., Herbert, E. W., J., \& Shimanuki, H. (1977). Supplemental Feeding of Honey Bee Colonies. United States Department of Agriculture, Agriculture Information Bulletin No. 413, 8 pages.

[7] Delaplane, K. S., Steen, van der J., Guzman-Novoa, E. (2013) Standard methods for estimating strength parameters of Apis mellifera colonies. In: Dietemann, V., Ellis, J. D., Neumann P. (eds.) The COLOSS BEEBOOK, Volume I: standard methods for Apis mellifera research. Journal of Apicultural Research 52 (1): 1-12. doi: 10.3896/IBRA/1.52.1.03.

[8] IBM Corp. (2017). IBM SPSS statistics for windows, Armonk, New York.

[9] MacFawn, D. (2019) Feeders - Every feeder has its strengths and drawbacks. Bee Culture The Magazine of American Beekeeping 1-6. Available at: https://www.beeculture.com

[10] Abou-shaara, H. F. (2016) A simple method for feeding honey bees. Bees for Development 101: 3.

[11] Liseki, S. D. (1996) Sugar feeding using a top-bar feeder. Bee for Development 38, 1.

[12] Andere, C., Palacio, M. A., Rodriguez, E. M., Figini, E., Dominguez, M. T., Bedascarrasbure, E. (2002) Evaluation of the defensive behavior of two honeybee ecotypes using a laboratory test. Genetics and Molecular Biology 25: 57-60. doi: 10.1590/S1415-47572002000100011.

[13] Patrice, K., Gideon, N. N., Paul, N. N., Christopher, A., Robert, K. (2018) Apis mellifera adansonii Is the Most Defensive Honeybee in Uganda. Psyche 2018: 4079587. doi: $10.1155 / 2018 / 4079587$.

[14] Alemu, T., Legesse, G., and Ararso, Z. (2014) Performance Evaluation of Honeybee (Apis mellifera scutellata) in Guji Zone. International Journal of Innovation and Applied Studies 9: 1987-1993.

[15] Blackiston, H. (2009) Beekeeping For Dummies. Wiley Publishing Inc., Indianapolis, Indiana. 358pp. 